\title{
DEZ ANOS DE PESQUISA CONTÁBIL NO BRASIL: ANÁLISE DOS TRABALHOS APRESENTADOS NOS ENANPADS DE 1996 A 2005
}

TENYEARS OFACCON NING RESEAROHINBRAZL: ANAYYSIS WTHPAPES OF ENANPADS FROM 1996 TO2005

\section{RESUMO}

Este trabal ho anal isa a evolução temporal da produção de pesquisa científica em Contabilidade no Brasil e a relação entre as abordagens normativa e positiva. Para isso, fundamenta-se em uma pesquisa descritiva documental com trabalhos apresentados nos Encontros Anuais da Associação Nacional de Programas de Pós-Graduação em Administração - ENAN PADs, de 1996 a 2005. Para avaliar a produtividade dos autores dos trabalhos, utilizou-se a análise bibliométrica (Lei de Lotka). Os resultados al inham-se com os obtidos por Fülbier e Sellhorn (2006) no âmbito europeu, revelam uma predominância da abordagem positiva, indicam que poucos pesquisadores utilizam as duas abordagens e constatam uma produtividade mais baixa dos pesquisadores brasileiros, comparativamente aos que publicam em periódicos de língua inglesa.

\section{Octávio Ribeiro de Mendonça Neto}

Professor da Faculdade de Ciências Econômicas Contábeis e Administrativas, Universidade Presbiteriana Mackenzie - SP, Brasil

octavio.mendonca@mackenzie.com.br

\section{Edson Luiz Riccio}

Professor da Faculdade de Economia Administração e Contabilidade, Universidade de São Paulo - SP, Brasil

elriccio@usp.br

\section{Marici Cristine Gramacho Sakata}

Professora da Faculdade de Economia Administração e Contabilidade, Universidade de São Paulo - SP, Brasil

mcsakata@usp.br

Recebido em 18.09.2006. Aprovado em 15.07.2008.

Avaliado pelo sistema doubleblind review

Editor Científico: Rodrigo Bombonati

ABSTRACT his paper analyzes the temporal evolution of scientific accounting research in Brazil and the relationship between as normative and positive approaches. In order to do so, this study was based on documental descriptive research of papers submitted at the Annual M eeting of the $N$ ational Association of the Post-Graduation Programs in Management (ENAN PADs), from 1996 to 2005. Bibliometrics (Lotka's Law) was used to assess the productivity of the authors of the papers. The results are consistent with the results obtained by Fülbier and Sellhorn (2006) in Europe and reveal that authors predominantly adopt a positive approach, few researchers use the two approaches and confirm that Brazilian researchers have a lower productivity in comparison to those who publish in English-language periodicals.

PALAVRAS-CHAVE Pesquisa em contabilidade, paradigma, abordagem normativa, abordagem positiva, ENANPAD.

KEMORDS Accounting research, paradigm, normative, positive, EN AN PAD. 


\section{OCTÁVIO RIBEIRO DE MENDONÇA NETO •EDSON LUIZ RICCIO •MARICI CRISTINE GRAMACHO SAKATA}

\section{INTRODUÇÃO}

Esse artigo explora a abordagem metodológica adotada nos trabal hos sobre contabilidade apresentados nos Encontros Anuais da Associação dos Programas de Pós Graduação em Administração (ENAN PADs), no período de 1996 a 2005. Seu principal objetivo éanalisar a evolução temporal da produção de pesquisa científica em contabilidade no Brasil e a competição e a colaboração entre as abordagens normativa e positiva. Além disso, 0 artigo apresenta uma análise bibliométrica dessa produção com o objetivo de avaliar a produtividade dos pesquisadores brasileiros em contabilidade e o nível de concentração dessa produção, utilizando para tanto técnicas bibliométricas consagradas.

Most (1982, p. 1) declara que "um livro intitulado Accounting theory deveria começar com uma negação: 'N ão existe uma teoria geralmente aceita da contabilidade"'. Essa afirmativa é corroborada por Mattessich (1995, p. 156), quando afirma que

a Contabilidade, como a maioria dos esforços científicos, consiste em diferentes tradições de pesquisas que competem entre si e se complementam, e não em um único paradigma dominante (emergente de uma luta entre um paradigma precedente obsoleto e vário novos competidores).

Mattessich (1995) identifica, de forma ampla, três abordagens teóricas em contabilidade: a abordagem normativa (com ênfase nas preocupações analíticas); a abordagem positiva (com ênfase na pesquisa empírica e nos métodos estatísticos) e a crítico-interpretrativa (que contesta a neutral idade da contabilidade e enfatiza as normas éticas ao invés das pragmáticas, em particular as que concorrem para as metas sociais). Esta, vinculada à escola inglesa, desenvolveu-se a partir dos anos 1970 sob a liderança de Anthony Hopwood e do periódico Accounting, Organization and Society, por ele fundado. $\mathrm{N}$ a conclusão de seu trabalho, Mattessich (1995) propõe uma quarta abordagem que consiste em uma síntese entre a abordagem normativa e a positiva que denomina "normativocondicional". Essa abordagem, em última análise, consiste na criação de um grande número de model os contábeis, cada qual com uma hipótese customizada para um objetivo contábil específico, oferecendo um número considerável de escolhas aos usuários.

Fülbier e Sellhorn (2006), embora reconheçam que a pesquisa contábil tem empregado tradicional mente uma variedade de abordagens metodológicas e que a literatura tem discutido várias maneiras de classificá-las, consideram as abordagens normativa e positiva como predominantes. Esses autores focam seus trabal hos, que trata da pesquisa contábil no âmbito dos Congressos Anuais da European Accounting Association (EAA) na distinção fundamental entre pesquisa descritiva fact-based (positiva) ea pesquisa prescritiva value-based (normativa).

0 presente estudo restringiu-se à anal ise das pesquisas de contabilidade selecionadas para serem apresentadas nos EN AN PADs, único evento científico que, por ocasião da sua realização, enquadrava-se na classificação Qualis A, da Coordenação de A perfeiçoamento de Pessoal de Nível Superior (CAPES).

A análise da produção científica foi realizada em duas dimensões. A produção individual decada autor ea produção das Instituições de Ensino Superior (IES), a que esses autores estavam vinculados ao apresentarem seus trabal hos. 0 estudo preocupa-se também com os aspectos bibliométricos relacionados com a produtividade dos autores e o grau de concentração da pesquisa acadêmica contábil.

Este trabal ho contribui para a literatura científica da área ao apresentar uma estrutura metodológica para a análise das abordagens util izadas na pesquisa contábil e preencheuma lacuna ao analisar empiricamente uma mudança de paradigma na pesquisa contábil brasileira, ou seja, a substituição gradual da abordagem normativa pela abordagem positiva, substituição essa em linha com a constatação de Fülbier e Sellhorn (2006) no âmbito europeu.

0 artigo prossegue com a apresentação do objeto analisado e os procedimentos adotados para essa análise, os quais incluem o modelo bibliométrico utilizado. Em seguida, são apresentados uma breve revisão teórica dos principais conceitos relacionados com as abordagens normativa e positiva e o critério adotado para a classificação dos artigos conforme a abordagem empregada. $\mathrm{N}$ a seqüência, os resultados empíricos obtidos são discutidos, seguindo-se as conclusões e as sugestões para futuras pesquisas.

\section{OBJETO ANALISADO}

0 objeto analisado refere-se aos trabal hos sobre contabilidade apresentados nos ENAN PADs de 1996 a 2005. Em um primeiro momento, foram examinados todos os trabal hos apresentados, independentemente da temática na qual foram inscritos. Posteriormente, foram separados pela análise do título aqueles relacionados com a contabilidade. A classificação pelo título foi realizada pelo seu próprio significado, quando explícito, ou por meio de palavras-chave cujos significados mostravam al guma relação 
com o campo da contabilidade, como: contabilidade; contábil; custos; demonstrativos financeiros; demonstrativos contábeis; contador; controller; custeio; resultado; mensuração; avaliação; desempenho; rentabilidade; val or; lucro etc. Evidentemente, essa primeira classificação incluiu trabal hos não relacionados com a temática contábil. Em um segundo momento, foram analisados os resumos dos trabal hos selecionados pelos títulos e ainda, em caso de dúvida o texto integral do artigo, sendo excluídos aqueles não relacionados com a contabilidade. Os remanescentes foram classificados em positivos e normativos, com base no critério detal hado na seção que segue deste trabalho. Esse método de classificação não é isento de subjetividade, podendo ter sido descartados trabal hos que deveriam ter sido incluídos e vice-versa, principalmente em temas em que os campos da contabilidade, administração e finanças se sobrepõem.

Cabe observar ainda que a temática Contabilidade e Controle GERENCIAL (CCG) só foi introduzida nos ENANPADs a partir de 1998 e, mesmo em encontros posteriores a esta data, muitos trabal hos relacionados com a contabilidade foram inscritos em outras temáticas que não a CCG.

Esses trabal hos também foram objeto de análise quantitativa com o objetivo de se avaliar a produtividade dos autores que adotam cada uma das abordagens em questão, bem como o grau de concentração dessa produção. Utilizou-se para tanto o modelo de Lotka, bastante conhecido na área de cientometria e bibliometria.

Conforme Egghe e Rousseau (1990, p. 293), Lotka ao analisar o índice cumulativo de autores listados no Chemical Abstracts (1907-1916) e no Auerbach Geschichtstalfeln der Physik (1910) encontrou a seguinte regularidade: $a_{n}=\frac{C}{n^{c}}$ onde $a^{n}$ é o número de autores com n publicações e $c \approx 2$.

$\mathrm{Se} c=2$, e considerando-se T o número total de autores da amostra, realizando os cál cul os necessários tem-se $\mathrm{C} \approx 0,6079 \mathrm{~T}$. Isto significa que o número de autores que publica uma única vez $(n=1)$ corresponde a $60,79 \%$ do total de autores da amostra.

Assim, pode-se escrever que $a_{n}=a_{1} \cdot \frac{1}{n^{2}}$, onde $a_{1}$ denota o número de autores com uma única publicação e $a^{n}$ o número de autores com $n$ publicações. Dessa forma, o número de autores que publica duas vezes $(n=2)$ éigual a: $a_{2}=a_{1} \cdot \frac{1}{2^{2}}$. Realizando as substituições, tem-se: $a_{2}=0,6069 \mathrm{~T} \times 0,25=0,1517 \mathrm{~T}$, ou seja, $15,17 \%$ do total de autores da amostra, e assim sucessivamen- te. Posteriormente, essa Lei foi generalizada para: $a_{n}=a_{1} \cdot \frac{1}{n^{c}}$, em que, ao invés de se utilizar o expoente 2 , passou-se a utilizar um expoente genérico c a ser estimado caso a caso.

Em trabalhos internacionais relacionados com finanças e contabilidade, essa metodologia foi utilizada, entre outros, por Chung e Cox (1990) e Chung, Cox e Pak (1992).

No caso brasileiro, merece destaque o trabal ho de Urbizargástegui (2002), queaplicou essa metodologia para a produção científica brasileira em dez campos diferentes do conhecimento. Leal Oliveira e Soluri (2003) analisaram com essa metodologia a produtividade dos autores brasileiros na área de finanças e Cardoso e outros (2005) na área contábil.

Da mesma forma que os autores mencionados, este trabal ho utiliza a Lei de Lotka genérica, o que possibilita uma anál ise comparativa com os resul tados por el es obtidos. A lei genérica de Lotka é expressa por:

$a_{n}=a_{1} \cdot \frac{1}{n^{c}}$. O coeficiente c pode ser estimado por regressão linear, conforme segue: $\operatorname{Ln}\left(\frac{a_{n}}{a_{1}}\right)=-c \operatorname{Ln}(n)$. Um coeficiente estimado c maior do que 2, que é o previsto pela Lei de Lotka, revela que o número de autores com uma única publicação é maior do que o estabel ecido pela referida lei, o que significa, por um lado, menor produtividade dos autores, mas também menor concentração do conhecimento e vice-versa.

\section{PESQUISA NORMATIVA E PESQUISA POSITIVA EM CONTABILIDADE}

Alguns pesquisadores, como Morris (2006), advogam a adoção de abordagens metodológicas alternativas à positivista que, segundo ela, tem prevalecido na real ização de pesquisas em ciências sociais. As abordagens sugeridas pela autora são fundamentadas no pós-positivismo, na teoria crítica e no construtivismo.

Em contabilidade, embora a abordagem crítico-interpretativa venha apresentando importância crescente, principalmente no âmbito europeu (CHUA, 1986; BAXTER e CHUA, 2003; GENDRON e BAKER, 2005), as abordagens normativa e positiva ainda predominam, conforme observam Fülbier e Sellhorn (2006), o mesmo ocorrendo no Brasil, como se constatará no decorrer do presente trabalho.

A seguir, apresentam-se uma breve síntese das principais características dessas duas abordagens predominantes 
e a metodologia utilizada para classificar, em cada uma delas, os artigos objetos desse estudo.

\section{Abordagem positiva}

Watts e Zimmerman (1986), responsáveis pela sistematização da abordagem positiva na pesquisa contábil, afirmam que o objetivo da teoria contábil é explicar e prever a prática contábil. Explicar no sentido de evidenciar as razões para as práticas observadas e prever no sentido de antecipar fenômenos contábeis não observados, sendo que essas previsões podem ser testadas. Segundo ainda os autores, essa visão é denominada em Economia de Teoria Positiva para distingui-la das prescrições e argumentos normativos. Observam ainda que a terminologia foi popularizada pelo economista Milton Friedman na década de 1950 (WATTS e ZIM MERMAN, 1986).

Friedman (1967) observa que a economia positiva é, em princípio, independente de qual quer posição ética ou de quaisquer julgamentos e que sua função consiste em produzir um conjunto de generalizações que possa ser utilizado para prever as consequências de qual quer mudança das circunstâncias. 0 autor credita a introdução do conceito positivista em economia ao economista inglês J ohn Neville Keynes (1890), pai de John M aynard Keynes, que conceitua ciências positivas, normativas e arte:

Uma ciência positiva pode ser definida como um corpo sistematizado de conhecimento preocupado com o queé, uma ciência normativa ou reguladora como um corpo de conhecimento sistematizado relacionado com o que deveria ser [...]. 0 objetivo de uma ciência positiva éo estabelecimento denormalidades; o de uma ciência normativa, a determinação de um ideal, e o de uma arte, a formulação de prescrições (KEYNES, 1999, p. 22).

São esses conceitos utilizados inicialmente em economia por Friedman na década de 1950 que foram adotados pela contabilidade a partir do final da década de 1960, com o trabal ho pioneiro de Ball e Brown (1968). Em seguida, foram sistematizados e serviram de fundamento para a formulação da Teoria Positiva da Contabilidade por Watts e Zimmerman em Positive accounting theory, publicado em 1986.

Cabe observar, contudo, que, embora a abordagem positiva venha prevalecendo desde então nas pesquisas contábeis não só americanas, como também nas europeias, sua aceitação nunca foi unânime e recebeu críticas desde o início de seu desenvolvimento, como, por exemplo, em Christenson (1983), W hittington (1987), Sterling (1990) e Chambers (1993). Os próprios criadores da Teoria Positiva,
Watts e Zimmerman (1990), ao analisarem os resultados obtidos dez anos após a divulgação de seus primeiros trabaIhos, reconheceram a necessidade de aperfeiçoar a ligação entre a teoria e os resultados empíricos.

\section{Abordagem normativa}

Fülbier e Sellhorn (2006) observam que, embora seja difícil identificar um ponto de partida para a pesquisa contábil, as origens parecem estar na abordagem normativa, notadamente na Alemanha, onde teorias de contabilidade se desenvolveram no final do século XIX e início do século XX. De acordo com os autores, essa linha de pesquisa se preocupava, e ainda se preocupa, com questões normativas relacionadas com o que deveria constar dos demonstrativos financeiros e como esses elementos deveriam ser avaliados.

Mattessich (1995) observa que essa literatura tinha preocupações éticas, pois se baseava no princípio de que o homem de negócios tem o dever de otimizar a eficiência e a performance de sua empresa para benefício geral da sociedade. Em trabalho mais recente, M attessich e Kupper (2003) observam que parece não haver dúvida de que, durante a primeira metade do século XX, a liderança do pensamento contábil esteve concentrada na Alemanha. Salientam que a industrial ização acelerada desse país, a partir da metade do século XIX, foi acompanhada por uma série de pensamentos contábeis originais, todos com características formalistas e classificatórias.

Com relação à situação atual, Fülbier e Sellhorn (2006, p. 1) observam que os resultados da análise por el es realizada "corroboram a visão popular de que as pesquisas positivas são crescentemente dominantes". Embora essa conclusão limite-se à literatura contábil europeia, no caso americano essa preponderância é ainda mais profunda, pois, como observa M artins (2005, p. 3), "a revista mais respeitada em pesquisa contábil no mundo, a Accounting Review, que, no início da década de 60, publicava um ou outro trabal ho dessa natureza empírica positivista, hoje não tem lugar (já faz muito tempo) para outro tipo de trabalho".

\section{Critério para classificação em pesquisa normativa e pesquisa positiva}

De acordo com Fülbier e Sellhorn (2006), para analisar projetos de pesquisa específicos, há necessidade de um entendimento mais preciso que distingue uma abordagem normativa de uma positiva. Segundo os autores citados, essa distinção pode ocorrer em três níveis.

O primeiro nível está relacionado com o objetivo da 
pesquisa que pode ser positivo (descrever ou explicar uma prática contábil) ou normativo (recomendar políticas aos praticantes da contabilidade).

O segundo nível refere-se à questão da pesquisa que pode ser positiva ou normativa. O bservam, contudo, que a questão de pesquisa, seja ela de caráter positivo seja normativo, pode estar tanto relacionada a um objetivo positivo como a um objetivo normativo.

0 terceiro nível identificado pelos autores está relacionado com o método. Uma vez que este não está deterministicamente relacionado com a questão da pesquisa, prosseguem os autores, a distinção só pode ser identificada nos dois primeiros níveis. Isso introduz um grau de dificuldade adicional, já que os pesquisadores podem utilizar uma questão de pesquisa positiva com objetivos implicitamente normativos.

Os autores observam ainda que, embora a distinção entre o nível da questão de pesquisa (normalmente explícito) e o nível do objetivo da pesquisa (normalmente implícito) seja sutil, ele pode ser operacionalizado para aplicação em uma pesquisa empírica como a presente, adotando como pressuposto o conceito de que um pesquisador adepto da abordagem positiva não irá, em seus trabalhos, recomendar a adoção de qualquer prática contábil nem irá propor a fixação de padrões ou normas. Portanto, na pesquisa realizada no âmbito dos Congressos Anuais da EAA, os autores utilizaram como critério de classificação dos trabalhos apresentados 0 objetivo da pesquisa.

No presente trabalho, foi utilizado esse mesmo critério para a classificação, ou seja, o nível do objetivo da pesquisa. Dessa forma, classificou-se como normativa aquela em que o pesquisador declara explicitamente suas implicações ou relevância para a prática contábil e, como positivas, aquelas em que se explicita que os resultados obtidos contribuem para a compreensão de determinado fenômeno contábil. Cabe observar que esse critério serve apenas para classificar a pesquisa e não o pesquisador, já que se constatou neste trabalho que diversos pesquisadores realizaram tanto pesquisas normativas como positivas.

\section{APRESENTAÇÃO E ANÁLISE DOS RESULTADOS}

A seguir, são expostos e discutidos os resultados obtidos na análise da produção científica em contabilidade apresentada nos ENAN PADs no período de 1996 a 2005, tendo em vista tanto as produções científicas quanto os autores e as IES a que pertencem.

\section{Distribuição temporal da produção científica analisada}

Foram examinados durante o período em questão os títulos de todos os trabalhos publicados nos anais, independentemente da temática em que foram inscritos. Conforme a Tabela 1, esses trabalhos totalizam 4.582 títulos, dos quais 405 estão relacionados com a contabilidade, o que significa uma participação de $8,84 \%$ no total de trabal hos apresentados.

Os dados da Tabela 1 revelam que, até 1998, a participação dos trabalhos de contabilidade nos ENANPADs nunca esteve acima de $5 \%$. A partir dessa data, observa-se crescimento da participação que chega a atingir $12,42 \%$, em 2004, e 12,09\%, em 2005.

Do total de 405 trabal hos de contabilidade publicados nos anais durante o período em questão, 333 adotaram uma abordagem positiva, representando $82,22 \%$ do total, enquanto 72 utilizaram uma abordagem normativa, o equivalente a $17,78 \%$ do total.

Os resultados obtidos revelam ainda que até 1999, com exceção de 1997, havia um equilíbrio relativo entre as duas abordagens. A partir de então, a abordagem positiva passou a predominar e, em 2004 e 2005, chegou a participar com cerca de $90 \%$ dos trabal hos apresentados. Essa evolução temporal pode ser mais bem visualizada no Gráfico 1.

\section{Análise quantitativa da produção científica por instituiçẫo de ensino superior}

Os 405 trabalhos de contabilidade publicados nos anais dos ENAN PADs foram elaborados por 596 autores. Destes, 7 declararam o nome da empresa nas quais prestavam serviços e não mencionaram vinculação a qualquer Instituição de Ensino Superior (IES). Os demais 589 autores pertencem a 94 IES diferentes, das quais 10 são estrangeiras.

Como muitas das pesquisas foram realizadas em coautoria, algumas com até seis pesquisadores e como esses pesquisadores que realizam trabal hos em conjunto nem sempre pertencem a uma mesma IES, adotou-se o critério de considerar cada participação de cada pesquisador, independentemente de a participação ter sido individual ou em conjunto, como sendo uma participação integral e transferiu-se essa participação para a sua respectiva IES.

Com isso, os 405 trabal hos transformaram-se em 900 participações, das quais 745 com abordagem positiva e 155 , normativa. Os resultados podem ser observados na Tabela 2.

Esses resultados revelam que a FEA-USP foi a IES que mais contribuiu para produção da pesquisa científica em 
OCTÁVIO RIBEIRO DE MENDONÇA NETO •EDSON LUIZ RICCIO •MARICI CRISTINE GRAMACHO SAKATA

Tabela 1 - Evolução temporal da produção científica em contabilidade

\begin{tabular}{|c|c|c|c|c|c|c|c|}
\hline \multirow{2}{*}{ ENANPAD } & $\begin{array}{c}\text { TOTAL } \\
\text { ARTIGOS }\end{array}$ & \multicolumn{3}{|c|}{ ARTIGOS DE CONTABILIDADE } & \multicolumn{3}{|c|}{ ARTIGOS DE CONTABILIDADE } \\
\cline { 2 - 8 } & A & $\begin{array}{c}\text { TOTAL } \\
\text { B }\end{array}$ & $\begin{array}{c}\text { POSITVA } \\
\text { C }\end{array}$ & $\begin{array}{c}\text { NORMA } \\
\text { D }\end{array}$ & $\begin{array}{c}\text { TOTAL } \\
\text { B/A }-\%\end{array}$ & $\begin{array}{c}\text { POSITIVA } \\
\text { C/ B - \% }\end{array}$ & $\begin{array}{c}\text { NORMA } \\
\text { D/ B - \% }\end{array}$ \\
\hline 1996 & 280 & 9 & 5 & 4 & 3,21 & 55,56 & 44,44 \\
\hline 1997 & 241 & 6 & 5 & 1 & 2,49 & 83,33 & 16,67 \\
\hline 1998 & 250 & 13 & 7 & 6 & 5,20 & 53,85 & 46,15 \\
\hline 1999 & 270 & 14 & 11 & 3 & 5,19 & 78,57 & 21,43 \\
\hline 2000 & 364 & 29 & 25 & 4 & 7,97 & 86,21 & 13,79 \\
\hline 2001 & 424 & 25 & 15 & 10 & 5,90 & 60,00 & 40,00 \\
\hline 2003 & 566 & 53 & 43 & 10 & 9,54 & 81,13 & 18,87 \\
\hline 2004 & 629 & 65 & 52 & 13 & 10,33 & 80,00 & 20,00 \\
\hline Total & 781 & 97 & 86 & 11 & 12,42 & 88,66 & 11,34 \\
\hline
\end{tabular}

Gráfico 1 - Distribuição temporal da produção científica em contabilidade

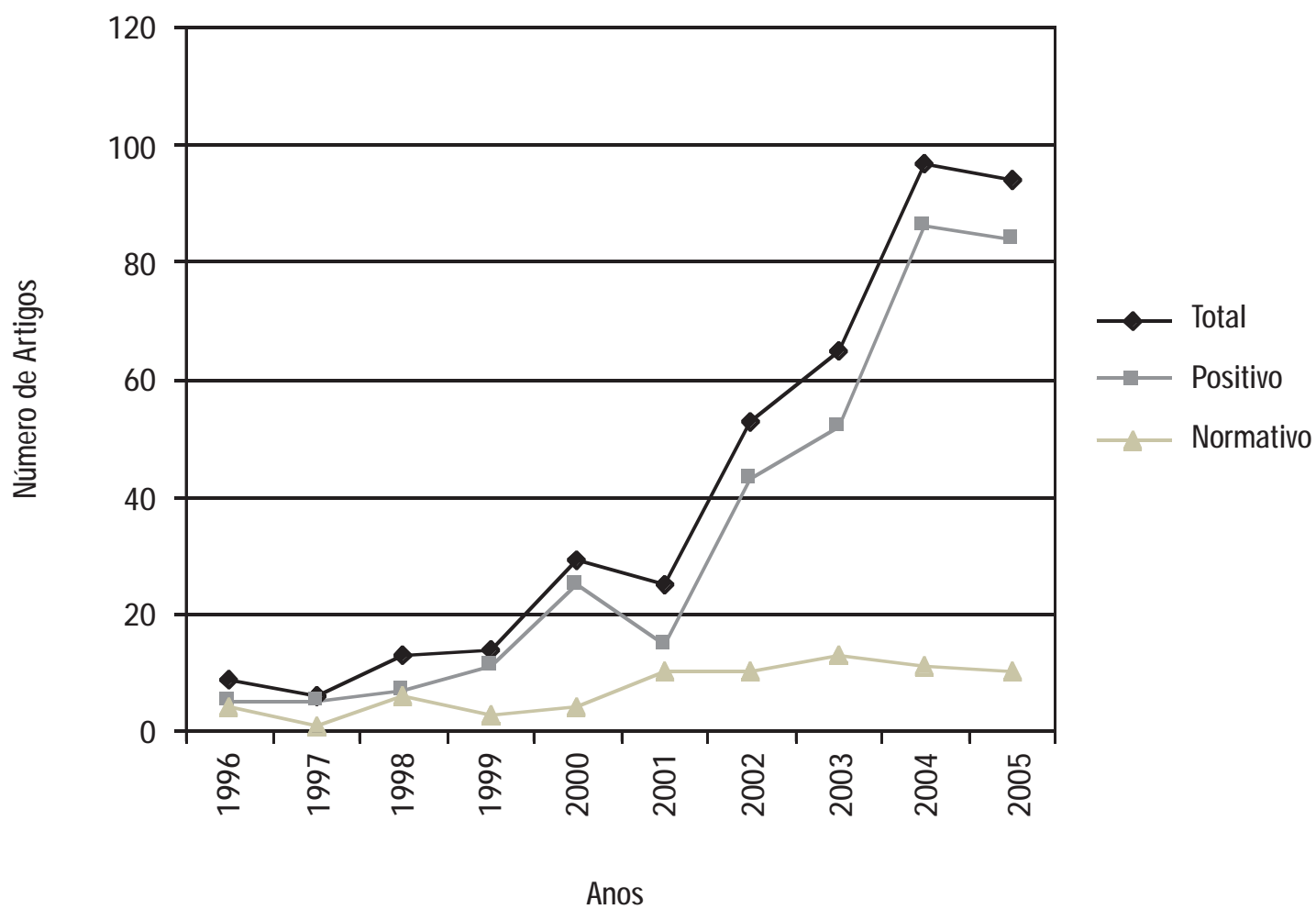


Tabela 2 - Produção científica em contabilidade por IES

\begin{tabular}{|c|c|c|c|c|c|c|}
\hline \multirow{2}{*}{ INSTITUIÇÃO } & \multicolumn{2}{|c|}{ TOTAL } & \multicolumn{2}{|c|}{ POSITIVA } & \multicolumn{2}{|c|}{ NORMATIVA } \\
\hline & № & $\%$ & № & $\%$ & № & $\%$ \\
\hline FEA-USP & 203 & 22,56 & 156 & 20,94 & 47 & 30,32 \\
\hline UNB/ UFPB/ UFPE/ UFRN (1) & 61 & 6,78 & 36 & 4,83 & 25 & 16,13 \\
\hline FUCAPE & 61 & 6,78 & 58 & 7,79 & 3 & 1,94 \\
\hline UFRJ & 51 & 5,67 & 41 & 5,50 & 10 & 6,45 \\
\hline UNISINOS & 45 & 5,00 & 45 & 6,04 & 0 & 0,00 \\
\hline PUC-SP & 38 & 4,22 & 28 & 3,76 & 10 & 6,45 \\
\hline UFMG & 32 & 3,56 & 32 & 4,30 & 0 & 0,00 \\
\hline UFRGS & 27 & 3,00 & 16 & 2,15 & 11 & 7,10 \\
\hline UFSC & 27 & 3,00 & 25 & 3,36 & 2 & 1,29 \\
\hline FGV-SP & 25 & 2,78 & 25 & 3,36 & 0 & 0,00 \\
\hline UFPE & 23 & 2,56 & 20 & 2,68 & 3 & 1,94 \\
\hline MACKENZIE & 19 & 2,11 & 19 & 2,55 & 0 & 0,00 \\
\hline FECAP & 18 & 2,00 & 14 & 1,88 & 4 & 2,58 \\
\hline FUND. VISCONDE DE CAIRU & 18 & 2,00 & 18 & 2,42 & 0 & 0,00 \\
\hline PUC-RIO & 14 & 1,56 & 14 & 1,88 & 0 & 0,00 \\
\hline UFC & 14 & 1,56 & 13 & 1,74 & 1 & 0,65 \\
\hline U. DE FORTALEZA & 14 & 1,56 & 14 & 1,88 & 0 & 0,00 \\
\hline UNB & 10 & 1,11 & 7 & 0,94 & 3 & 1,94 \\
\hline UFBA & 11 & 1,22 & 10 & 1,34 & 1 & 0,65 \\
\hline CONSÓRCIO-UEL/UEM & 9 & 1,00 & 9 & 1,21 & 0 & 0,00 \\
\hline PUC-MG & 9 & 1,00 & 9 & 1,21 & 0 & 0,00 \\
\hline I. E. S. JUDAS TADEU & 8 & 0,89 & 0 & 0,00 & 8 & 5,16 \\
\hline UFRRJ & 8 & 0,89 & 8 & 1,07 & 0 & 0,00 \\
\hline U. METODISTA DE SP & 8 & 0,89 & 8 & 1,07 & 0 & 0,00 \\
\hline FAC. DE BOA VIAGEM & 7 & 0,78 & 7 & 0,94 & 0 & 0,00 \\
\hline F.U. R. DE BLUMENAU & 6 & 0,67 & 6 & 0,81 & 0 & 0,00 \\
\hline OUTRAS (2) & 134 & 14,89 & 107 & 14,36 & 27 & 17,42 \\
\hline TOTAL & 900 & 100,00 & 745 & 100,00 & 155 & 100,00 \\
\hline
\end{tabular}

Notas:

(1) Refere-se ao Programa Conjunto de Pós-Graduação em Contabilidade das Universidades Federais de Brasília, Paraíba, Pernambuco e Rio Grande do Norte.

(2) Refere-se a 68 IES e 7 empresas, todas com menos de 5 participações cada uma. 
contabilidade no período em questão. Individual mente, foi responsável por cerca $22,56 \%$ da produção total, $20,94 \%$ da pesquisa positiva e $30,32 \%$ da pesquisa normativa.

\section{Análise quantitativa da produção científica por autor} Da mesma forma que na análise quantitativa da produção científica por IES, adotou-se o critério de considerar cada participação de cada pesquisador, independentemente de sua participação ter sido individual ou em conjunto, como sendo uma participação integral. Com isso, os 405 trabalhos produzidos pelos 589 autores transformaramse em 900 participações, das quais 745 com abordagem positiva e 155, normativa.

As Tabelas 3, 4 e 5 apresentam, respectivamente, o número de autores em ordem decrescente de participações na produção total, na produção de pesquisa com abordagem positiva e na de abordagem normativa. Esses dados servem de base para o cálculo do coeficiente $c$ da Lei de Lotka generalizada que será apresentado na sequência.

Com base nos dados dessas tabelas, calculou-se 0

Tabela 3 - Número de autores por ordem decrescente de participação na produção total

\begin{tabular}{|c|c|c|}
\hline № DE PARTICIPAÇÕES & № DE AUTORES & TOTAL DE PARTICIPAÇÕES \\
\hline 9 & 1 & 9 \\
\hline 8 & 2 & 16 \\
\hline 7 & 3 & 21 \\
\hline 6 & 4 & 24 \\
\hline 5 & 8 & 40 \\
\hline 4 & 12 & 48 \\
\hline 3 & 48 & 144 \\
\hline 2 & 80 & 160 \\
\hline 1 & 438 & 438 \\
\hline TOTAL & 596 & 900 \\
\hline
\end{tabular}

Tabela 4 - Número de autores por ordem decrescente de participação na produção de pesquisa positiva

\begin{tabular}{|c|c|c|}
\hline NNo DE PARTICIPAÇÕES & No DE AUTORES & TOTAL DE PAR TCIPAÇÕES \\
\hline 8 & 2 & 16 \\
\hline 7 & 2 & 14 \\
\hline 6 & 1 & 6 \\
\hline 5 & 10 & 50 \\
\hline 4 & 9 & 36 \\
\hline 3 & 35 & 105 \\
\hline 2 & 57 & 114 \\
\hline 1 & 404 & 404 \\
\hline 0 & 76 & 0 \\
\hline TOTAL & 596 & 745 \\
\hline
\end{tabular}


coeficiente c da Lei de Lotka generalizada, ou seja, $a_{n}=a_{1} \cdot \frac{1}{n^{c}}$, sendo:

$a_{1}=$ número de autores que publica um único artigo

$a_{n}=$ número de autores que publica $n$ artigos

$\mathrm{n}=$ número de artigos

0 coeficiente $c$ foi estimado por regressão linear, conforme segue:

$$
\operatorname{Ln}\left(\frac{a_{n}}{a_{1}}\right)=-c \operatorname{Ln}(n)
$$

Os resultados obtidos podem ser observados na Tabela 6, que inclui também o coeficiente de correlação r e o coeficiente de determinação $R^{2}$.
Os dados anteriores revelam coeficientes de correlação $r$ satisfatórios, todos el es com um grau de confiança superior a $95 \%$. Os coeficientes de determinação $R^{2}$ revelam forte poder explicativo do modelo. Os coeficientes c estimados por regressão linear revelaram-se todos eles superiores a 2. Isso significa que a produtividade dos autores de contabilidade é inferior àquela constatada por Lotka e denota que o conhecimento na área contábil está menos concentrado do que o previsto pela referida lei da bibliometria.

A Tabela 7 compara os coeficientes $c$ apresentados na Tabela 6 com aqueles encontrados por Chung, Cox e Pak (1992), Leal, Oliveira e Soluri (2003) e Cardoso e outros (2005).

Chung, Cox e Pak (1992) analisaram a produtividade de autores na área contábil que publicaram seus trabal hos

Tabela 5 - Número de autores por ordem decrescente de participação na produção de pesquisa normativa

\begin{tabular}{|c|c|c|}
\hline № DE PAR TICIPAÇÕES & № DE AUTORES & TOTAL DE PARTICIPAÇÕES \\
\hline 6 & 1 & 6 \\
\hline 5 & 0 & 0 \\
\hline 4 & 0 & 0 \\
\hline 3 & 7 & 21 \\
\hline 2 & 20 & 40 \\
\hline 1 & 88 & 88 \\
\hline 0 & 480 & 0 \\
\hline TOTAL & 596 & 155 \\
\hline
\end{tabular}

Tabela 6 - Coeficiente c da lei de Lotka generalizada

\begin{tabular}{|l|c|c|c|}
\hline \multicolumn{1}{|c|}{ TIPO DE PESQUISA } & C & r & R $^{2}$ \\
\hline Pesquisa Total & 2,7204 & 0,9919 & 0,9839 \\
\hline Pesquisa Positiva & 2,7921 & 0,9582 & 0,9181 \\
\hline Pesquisa Normativa & 2,2863 & 0,9987 & 0,9973 \\
\hline
\end{tabular}

Tabela 7 - Coeficiente c da lei de Lotka generalizada - análise comparativa

\begin{tabular}{|l|c|c|c|c|c|}
\hline \multicolumn{1}{|c|}{ TIPO DE PESQUISA } & AMOS TRA EM QUESTÃO & LOTKA & CHUNG & LEAL & CARDOSO \\
\hline Pesquisa Total & 2,7204 & & & \\
\hline Pesquisa Positiva & 2,7921 & 2,00 & 1,87 & 2,44 & 2,54 \\
\hline Pesquisa Normativa & 2,2863 & & & \\
\hline
\end{tabular}


em 14 periódicos de língua inglesa no período de 1968 a 1988. Leal, Oliveira e Soluri (2003) analisaram a produção brasileira em finanças, no período de 1974 a 2001, examinando os trabalhos publicados pelos principais periódicos científicos nacionais da área, além dos anais dos EN AN PADs. Já Cardoso e outros (2005) anal isaram a produção científica brasileira em contabilidade no período de 1990 a 2003, examinando os trabal hos publicados nos periódicos científicos da área de administração classificados como "A" pelo critério da CAPES.

Conforme se observa na Tabela 7, os coeficientes c obtidos para toda a pesquisa atual, sem distinção de abordagem, apresentam valores cerca de $7 \%$ acima dos obtidos por Cardoso e outros (2005), 11\% acima dos obtidos por Leal, Oliveira e Soluri (2003) e 44\% acima daqueles registrados por Chung, Cox e Pak (1992). Embora esses resultados sugiram que os pesquisadores brasileiros em contabilidade apresentam produtividade significativamente inferior aos que publicam em língua inglesa e também um pouco abaixo daquela apresentada pelos autores nacionais da área de finanças, deve-se salientar que a pesquisa brasileira em contabilidade ainda não atingiu o mesmo grau de maturidade de áreas afins e que seus pesquisadores dispõem de poucos periódicos e eventos para divulgar a sua produção. 0 próprio evento analisado no presente estudo é destinado ao campo da administração, em que a contabilidade aparece apenas como uma das temáticas. Com relação à abordagem, observa-se que a normativa é a que apresenta maior produtividade, chegando a superar aquela da área de finanças.

\section{Análise quantitativa da abordagem adotada por autor} Dos 596 autores, 438 tiveram uma única participação, enquanto 158 participaram em mais de um trabal ho. Ainda com relação aos 596 autores, 480 adotaram exclusivamente a abordagem positiva; 76, a normativa; e 40, ambas. Esse resultado sugere que a pesquisa sistemática em contabilidade, na época da realização deste estudo, está limitada, no máximo, ao trabal ho de 158 pesquisadores. Considerando apenas esses 158 autores que participaram mais de uma vez, 98 adotaram exclusivamente a abordagem positiva, 20, a normativa, e 40, ambas. Considerando os 438 autores que participaram uma única vez, 382 adotaram a abordagem positiva e 56, a normativa. Esses dados são apresentados na Tabela 8.

\section{CONSIDERAÇÕES FINAIS}

Este trabal ho objetivou contribuir para o entendimento da produção científica recente em contabilidade no Brasil, por meio da análise da evolução temporal da produção da mesma, da competição e da colaboração entre as abordagens positiva e normativa.

Os resultados obtidos, que se referem ao período de 1996 a 2005 e que estão limitados ao âmbito dos ENAN PADs, revelam de forma inequívoca predominância da pesquisa positiva. Essa predominância é representada por sua adoção em $82 \%$ dos trabalhos ( 333 de 405), em $83 \%$ das participações ( 745 de 900 ) , e por $81 \%$ dos autores ( 480 de 596). Essa adoção pelos autores da abordagem positiva sobe para $87 \%$ (520 de 596 ) se incluirmos os 40 autores que adotaram as duas abordagens. Os autores que adotaram, exclusivamente, a abordagem normativa limitam-se a $13 \%$ do total ( 76 de 596 ).

Em termos de evolução temporal, a participação da abordagem positiva passou de $56 \%$ do total de trabal hos apresentados em 1996 ( 5 em um total de 9) para 89\% em 2005 (84 em um total de 94). Esses resultados estão alinhados com aqueles obtidos por Fülbier eSellhorn (2006), no âmbito dos Congressos Anuais da European Accounting Association. Segundo esses autores, a predominância da abordagem positiva nesses Congressos evoluiu de $63 \%$, em 2000, para 79\%, em 2005.

Tabela 8 - Abordagem adotada pelos autores

\begin{tabular}{|l|c|c|c|}
\hline \multicolumn{1}{|c|}{ TIPO DE PESQUISA } & $\begin{array}{c}\text { PESQUISADORES COM } \\
\text { PARTCIPAÇÃO } \\
\text { ÚNICA }\end{array}$ & $\begin{array}{c}\text { PESQUSADORES COM } \\
\text { MAIS DE UMA } \\
\text { PARTICIPAÇÃO }\end{array}$ & TOTAL \\
\hline Pesquisa Positiva & 382 & 98 & 480 \\
\hline Pesquisa Normativa & 56 & 20 & 76 \\
\hline Ambas & - & 40 & 40 \\
\hline TOTAL & 438 & 158 & 596 \\
\hline
\end{tabular}


O utro aspecto a ser destacado é a baixa produtividade dos pesquisadores, constatada por meio dos coeficientes c da Lei de Lotka generalizada, que resultou em 2,72 para o conjunto das pesquisas, 2,79 para a pesquisa positiva e 2,28 para a pesquisa normativa, val ores esses bem superiores ao encontrado por Chung, Cox e Pak (1992) para os pesquisadores de contabilidade que publicam em língua inglesa. Todavia, conformejá sal ientado, deve-se considerar que a pesquisa brasileira em contabilidade ainda não atingiu o grau de maturidade observado em outras áreas de conhecimento afins, como economia e finanças, e que seus pesquisadores dispõem de poucos periódicos e eventos para divulgar a sua produção.

Ainda com relação aos autores, é importante frisar a baixa participação daquel es que utilizaram as duas abordagens. A penas 40 de um total de 158 pesquisadores que tiveram mais de uma participação, ou seja, $25 \%$. Isso sugere que a colaboração entre pesquisadores que adotam essas duas abordagens é modesta, predominando, assim, a competição entre eles, com significativo crescimento da abordagem positiva.

Cabe observar ainda que a FEA-USP responde individualmente por parte importante das participações na produção da pesquisa em contabilidade. Essa constatação não surpreende, uma vez que o seu programa de pós-graduação em contabilidade é o mais antigo em funcionamento no país e o único que mantinha, na data da pesquisa, um curso em nível de doutorado. Todavia, essa partici pação não é dominante, representando $23 \%$ do total da pesquisa real izada no horizonte de tempo em questão, $21 \%$ da pesquisa positiva e $30 \%$ da normativa. Merecem destaquetambém o programa conjunto UNB/UFPB/UFPE/ UFRN responsável por $16 \%$ das pesquisas normativas e a FUCAPE, cujo programa de pós-graduação é mais recente e que já é responsável por cerca de $8 \%$ das pesquisas positivas. Cumpre salientar ainda que esses resultados são apenas quantitativos, não fornecendo qual quer indicação a respeito da qualidade da pesquisa realizada.

Por ultimo, salienta-se que uma discussão profunda a respeito da influência dos programas de pós-graduação na determinação dos paradigmas de pesquisa a serem utilizados por seus discentes e docentes faz-se necessária. As abordagens normativa e positiva não são exclusivas e paradigmas alternativos, como o pós-positivismo, a teoria crítica e o construtivismo, sugeridos por Morris (2006) para a pesquisa em ciências sociais, devem ser considerados pelos responsáveis pelas disciplinas de metodologia científica desses programas. O utro aspecto a ser ressaltado é o incentivo à interdisciplinaridade com a incorporação de teorias oriundas da sociologia e da psicologia, entre outras, nas pesquisas contábeis, notadamente aquel as relacionadas com a busca de explicações para os aspectos comportamentais e as relações de poder nesse campo.

Para futuras pesquisas, sugere-se a ampliação da base de dados, incluindo outros congressos, periódicos, teses e dissertações; a realização de análises comparativas com outros países, salientan do a causa de eventuais diferenças encontradas, que podem estar relacionadas com o sistema legal adotado em cada país a aspectos econômicos e culturais; a análise dos motivos que ainda não possibilitaram o desenvolvimento no Brasil, de forma significativa, de uma abordagem crítico-interpretativa na contabilidade ao estilo da escola inglesa; e a realização de estudos que analisem até que ponto a ideologia que predominou no Brasil nos últimos anos, baseada no liberal ismo econômico, na apologia da privatização e da desregulamentação, é responsável pela predominância da abordagem positiva na pesquisa contábil entre nós.

\section{REFERÊNCIAS}

BAXTER, J; CHUA, W. F. Alternative management accounting research whence and whither, Accounting, Organizations and Society, v. 28, n. 2, p. 97-126, 2003.

BALL, R; BROWN , An empirical evaluation of accounting income numbers, Journal of Accounting Research, v. 6, n. 2, p. 159-177, 1968.

CARDOSO, R. L; MENDONÇA NETO, O. R. de; RICCIO, E. L; SAKATA, M. C. G. Pesquisa científica em contabilidade entre 1990 e 2003. RAErevista de administração de empresas, v. 45, n. 2, p. 34-45, 2005.

CHAMBERS, R. J. Positive accounting theory and the PA cult. Abacus, v. 29, n. 1, p. 1-26, 1993.

CHRISTENSON, C. The methodology of positive accounting. Accounting Review, v. 58, n. 1, p. 1-22, 1983.

CHUA, W. F. Radical developments in accounting thought. The Accounting Review, v. 61, n. 4, p. 601-632, 1986.

CHUNG, K. H; COX, R A. K. Patterns of productivity in the finance literature: a study of the bibliometric distributions. The Journal of Finance, $v$. 45, n. 1, p. 301-309, 1990.

CHUNG, K. H; COX, R. A. K; PAK, H. S. Patterns of research output in the accounting literature: a study of the bibliometric distributions. Abacus, v. 28, n. 2, p. 168-185, 1992.

EGGHE, L; ROSSEAU, R. Introduction to informetrics: quantitative methods in library, documentation and information science. Amsterdam: Elsevier Science Publishers, 1990. 
FRIEDMAN, M. Ensayos sobre economía positiva. Madrid: Editorial Gredos, 1967.

FÜLBIER, R. U; SELLHORN, T. M ethodological approaches to accounting research: evidence from EAA annual congresses. EAA Annual Congress, Dublin, 2006.

GENDRON, Y; BAKER, C. R. On interdisciplinary movements: the development of a network of support around foucaultian perspectives in accounting research. European Accounting Review, v. 14, n. 3, p. 525-569, 2005.

KEYNES, J. N. The scope and method of political economy. Batoche Books, 1999. Disponível em: বhttp://members.tripod.com/rodhay/batochebooks. $\mathrm{html}>$. Acesso em 06.04.2006.

LEAL, R. P. C; OLIVEIRA, J; SO LURI, A. F. Perfil da pesquisa em finanças no Brasil. RAE-revista de administração de rmpresas, v. 43, n. 1, p. 91-103, 2003.

MATTESSICH, R. Critique of accounting: examination of the foundations and normative structure of an applied discipline. Westport: Quorum Books, 1995

MATTESSICH, R; KUPPER, U. Accounting research in german language area - first half of the 20th century. Review of Accounting and Finance, $v$. 2, n. 3, p. 103-137, 2003
MARTINS, E. Normativismo e/ou positivismo em contabilidade: qual 0 futuro? Revista de Contabilidade \& Finanças, v. 16, n. 39, p. 3, 2005.

MORRIS, T. Social work research methods: four alternative paradigms. Thousand Oaks: Sage Publications, Inc. 2006.

MOST, KENNETH S. Accounting theory. 2nd ed. Columbus: Grid Publishing, 1982.

STERLING, R. R. Positive accounting: an assessment. Abacus, v. 26, n. 2, p. $97-135,1990$

URBIZARGÁSTEGUI, A. R. A Lei de Lotka na bibliometria brasileira. Ciência da Informação, v. 31, n. 2, p. 14-20, 2002.

WATTS, R. L; ZIM MERMAN, J. L. Positive accounting theory. Upper Saddle River: Prentice Hall, 1986.

WATTS, R. L; ZIMMERMAN, J. L. Positive accounting theory: a ten years perspective. Accounting Review, v. 65, n. 1, p. 131-156, 1990.

WHITTINGTON, G. Positive theory: a review article. Accounting and Business Research, v. 17, n. 68, p. 327-336, 1987.

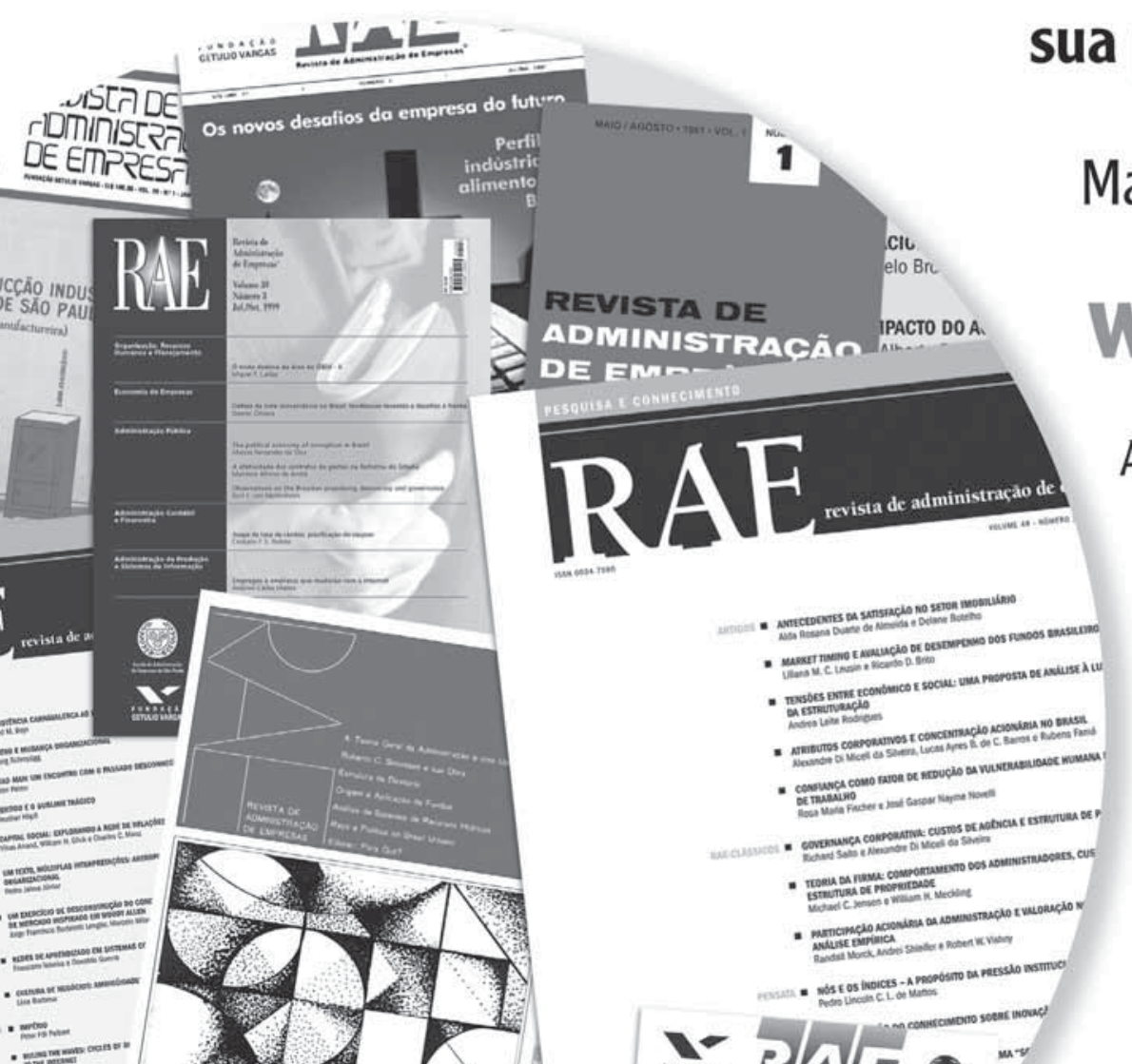

\section{Acesse 0 acervo histórico da RAE desde sua primeira edição, em 1961.}

Mais de 2.000 artigos na íntegra. www.fgv.br/rae

A disponibilização do acervo completo da RAE é mais uma iniciativa de RAE-publicações para apoiar professores e pesquisadores.

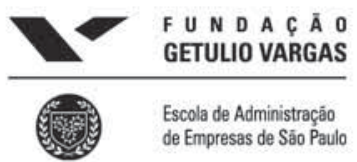

